\title{
PCR as diagnostic tool in early detection of extra pulmonary tuberculosis
}

\author{
Manali Shah ${ }^{1}$, Ullas Bhabhor ${ }^{2, *}$, Yogita Mistry ${ }^{3}$, Summaiya Mullan ${ }^{4}$ \\ ${ }^{1}$ Resident, ${ }^{2}$ Assistant Professor, ${ }^{3}$ Microbiologist, ${ }^{4}$ Ex Professor \& HOD, ${ }^{1,2,4}$ Dept. of Microbiology,,${ }^{1,3,4}$ Government Medical \\ College, New Civil Hospital, Surat, Gujarat, ${ }^{2}$ Stem Cell Therapy Institute, New Civil Hospital, Surat, Gujarat, India
}

*Corresponding Author:

Email: dr.ullas1357@yahoo.in

\begin{abstract}
Introduction: Extra-pulmonary tuberculosis is a major public health issue with a significant cause of morbidity and mortality in developing countries. Diagnosis is difficult due to various clinical presentations and pauci-bacillary nature. The less number of tubercular bacteria at extra-pulmonary sites may cause diagnostic difficulty demanding for rapid, sensitive and specific test.

Material and Methods: It was a 1 year retrospective study in tertiary care hospital. Different extra-pulmonary samples received by laboratory were included in the study. Microscopy by ZN stain, culture on Lowenstein-Jensen media and RT-PCR on ABI 7300 was performed after decontamination of the samples using $4 \% \mathrm{NaOH}$ and $2.9 \%$ sodium citrate.

Results: Total 300 extra-pulmonary samples were tested. 122 samples were positive by either method. Sensitivity of PCR was $59 \%$. ZN microscopy and culture method showed $46 \%$ and $48 \%$ sensitivity respectively. Tubercular bacilli were isolated were mainly body fluids, pus and endometrial biopsy. The most common age group affected was 20-29 years.

Conclusion: PCR is still a good diagnostic tool for extra-pulmonary tuberculosis even if CBNAAT is available. Even more comparative studies should be done between different molecular methods, so that in future the best option for diagnosis of extrapulmonary tuberculosis without much more false negative results will be available.
\end{abstract}

Keywords: Extra pulmonary, Tuberculosis, PCR.

\section{Introduction}

Extra pulmonary tuberculosis is a major public health issue existing for centuries. It accounts for almost $20 \%$ of tuberculosis in India. ${ }^{1}$ It is a milder form of infective disease as compared to pulmonary tuberculosis. ${ }^{2}$ It includes lymphatic, genital, gastrointestinal, pleural, pericardial, skeletal or any other organ or viscera. Tuberculous lymphadenitis is the most common extra pulmonary presentation followed by pleural effusion and endometritis. It is a significant cause of morbidity and mortality in developing countries. Diagnosis is difficult due to varities of clinical presentations and pauci-bacillary nature. Further, the tubercular bacteria at extra pulmonary sites are often less in number which increases the diagnostic difficulty in terms of more false negative results. ${ }^{3}$ The main disadvantage with this type of tuberculosis is undiagnosed and untreated patients. Conventional methods like microscopy and culture take pretty long time with very low sensitivity. ${ }^{4,5}$ There are other various methods like tuberculin skin test, serological tests, interferon gamma release assays (IGRA) etc. which have also failed to produce good reliable results. ${ }^{6}$ Therefore, rapid method with good sensitivity is required for better patient outcome. Molecular methods are the one with capacity to identify specific insertion sequence of the bacilli like IS6110, MPB64, 85mRNA, 16SrRNA and amplifying them. Some have capacity to identify specific genes like Gene expert detects rpoB gene, Hain detects gyrA, rrs and embB genes for XDR-TB. Thus increases the sensitivity and specificity of the test. It may be conventional PCR, real time PCR, nucleic acid amplification test and more. CBNAAT is an acceptable molecular method under RNTCP in diagnosis of extra pulmonary tuberculosis. But it does not have good sensitivity in few samples like pericardial fluid, ascitic fluid, synovial fluid with very low sensitivity in pleural fluid. There is still lack of knowledge about the best molecular method for diagnosis of extra pulmonary tuberculosis amongst CBNAAT, PCR, LAMP and many more. Our department was having PCR as a molecular method, so we have compared PCR sensitivity with conventional methods for extra pulmonary tuberculosis.

\section{Materials and Methods}

It was a retrospective study in tertiary care hospital for 1 year. Different extra pulmonary samples like pleural fluid, cerebrospinal fluid, endometrial biopsy, ascitic fluid, pus, pericardial fluid, broncho alveolar lavage, ovarian cyst fluid, urine, psoas muscle abscess, lymph node biopsy, any other drained fluid etc. from suspected case of extra pulmonary tuberculosis received by laboratory were included into the study. The samples were processed according to the standard protocol of the laboratory. Microscopy by ZN stain, culture on Lowenstein Jensen media and PCR on ABI 7300 was performed after decontamination of the samples using 4 $\% \mathrm{NaOH}$ and $2.9 \%$ sodium citrate. Commercial kit was available for PCR. It was performed according to user's manual and results were interpreted as per the kit literature. 85B mRNA was detected with TaqMan detector probe with the sequence 5'-(5carboxyfluoroscein [FAM])TCGAGTGACCCGGCATGGGAGCGT- $\left(N, N, N^{\prime}, N^{\prime}-\right.$ 
tetramethyl-6-carboxyrhodamine [TAMRA]). The results were entered into the Microsoft excel sheet and analyzed.

\section{Results}

Total 300 extra pulmonary samples were received in study duration. 122 were positive for extra pulmonary tuberculosis by either method. Sensitivity of PCR was $59 \%$. ZN microscopy and LJ solid culture method showed $46 \%$ and $48 \%$ sensitivity respectively. Table 1 shows $\%$ sensitivity of different methods. The samples from which tubercular bacilli isolated were pleural fluid, ascitic fluid, cerebrospinal fluid, endometrial biopsy, aspirate fluid, pus, psoas muscle abscess and fluid from right cheek. Table 2 shows different type of samples with \% of positivity amongst samples. Fig. 1 shows sample wise $\%$ positivity. The most common age group affected with EPTB was 20-29 (33\%)- young adults followed by 30-39 (22\%), 40-49 (15\%), 50-59 (12\%), 60-69 (7\%), 70-79 (7 \%), 10-19 (2\%) and 0-9 (2\%). Male: Female ratio was 2:1 showing male preponderance with $63 \%$.

Table 1: Sensitivity of different methods

\begin{tabular}{|l|c|}
\hline \multicolumn{1}{|c|}{$\begin{array}{c}\text { Laboratory method of } \\
\text { detection of Tuberculosis }\end{array}$} & $\begin{array}{c}\text { \% Sensitivity } \\
\text { of the method }\end{array}$ \\
\hline ZN stain & 46 \\
\hline PCR & 69 \\
\hline Culture (LJ medium) & 48 \\
\hline ZN + PCR + Culture positive & 22 \\
\hline ZN negative + PCR positive & 12 \\
\hline Culture negative + PCR positive & 23 \\
\hline
\end{tabular}

Table 2: Type of samples with their \% positivity amongst samples by PCR

\begin{tabular}{|l|c|c|c|}
\hline \multicolumn{1}{|c|}{ Type of samples } & $\begin{array}{c}\text { No. of total } \\
\text { samples received }\end{array}$ & $\begin{array}{c}\text { No. of Positive } \\
\text { samples }\end{array}$ & $\begin{array}{c}\text { \% of } \\
\text { Positive } \\
\text { samples }\end{array}$ \\
\hline Pleural fluid & 205 & 46 & $22 \%$ \\
\hline CSF & 35 & 2 & $2 \%$ \\
\hline AF & 29 & 5 & $5 \%$ \\
\hline Endometrial biopsy & 8 & 2 & $25 \%$ \\
\hline Aspirate fluid & 4 & 2 & $50 \%$ \\
\hline D \& C material & 3 & 0 & $0 \%$ \\
\hline Pus & 3 & 1 & $33 \%$ \\
\hline BAL & 3 & 0 & $0 \%$ \\
\hline Psoas muscle abscess & 2 & 1 & $50 \%$ \\
\hline Ovarian cyst fluid & 2 & 0 & $0 \%$ \\
\hline Pericardial fluid & 1 & 0 & $0 \%$ \\
\hline Urine & 1 & 0 & $0 \%$ \\
\hline Drain fluid & 1 & 0 & $0 \%$ \\
\hline Cervical LN biopsy & 1 & 0 & $0 \%$ \\
\hline EDTA blood & 1 & 0 & $0 \%$ \\
\hline Fluid from Right cheek & 1 & 1 & $100 \%$ \\
\hline
\end{tabular}

Fig. 1: Sample wise \% positivity

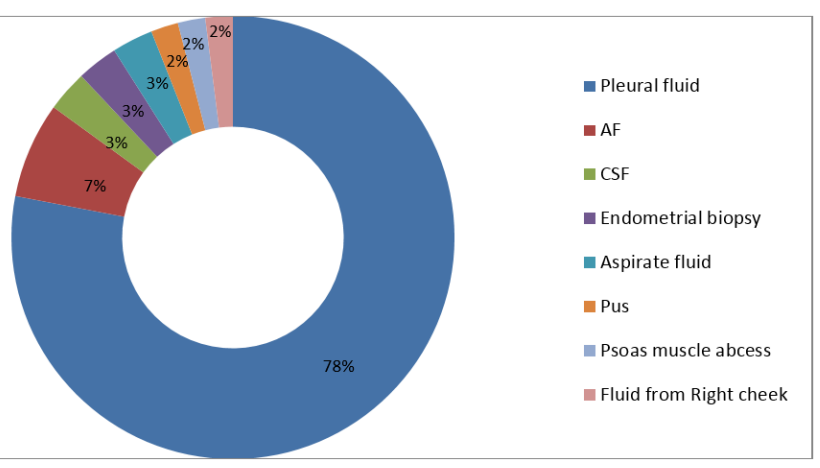

\section{Discussion}

The sensitivity of PCR for extra pulmonary tuberculosis in present study was $59 \%$ and specificity was $100 \%$ which shows similar results with Chakravorty et al, ${ }^{7}$ Honore et al, ${ }^{4}$ Maurya et al. ${ }^{8}$ The sensitivity of microscopy was $46 \%$ whereas of culture was $48 \%$. This is almost similar to Ganavalli S. Ajantha et $a l .{ }^{9}$ It seems that in present study sensitivity of PCR is almost $10 \%$ higher than the gold standard method which denotes the use of PCR for rapid and accurate results. PCR showed $8 \%$ positivity rate where both culture and microscopy were negative. In addition 
to that it showed $12 \%$ positivity in smear negatives and $23 \%$ positivity in culture negatives.

PCR showed $78 \%$ sensitivity in pleural fluid which matches with Amin et al. ${ }^{10}$ It shows $7 \%$ and $3 \%$ sensitivity for ascitic fluid and cerebrospinal fluid which is similar to Maurya et al. ${ }^{8}$ The sensitivity of endometrial biopsy was seen as $3 \%$ which mismatches with Bhanu et al, ${ }^{11}$ Gupta et al, ${ }^{12}$ Sharma et al, ${ }^{13}$ Abebe et $a l^{14}$ who showed sensitivity ranging from $20-60 \%$. Pus and Psoas muscle abscess shows total $6 \%$ sensitivity which is similar to Maurya et al. ${ }^{8}$ This shows that the sensitivity of PCR in pleural, abdominal, meningeal, endometritis tuberculosis is good.

The study shows maximum isolates from 20-39 years of age group with male predominance with Male: Female ratio as 2:1 in Surat which shows similarity with Chakravorty $e t a l^{7}$ and Siddiqui MAM et al. ${ }^{15}$

Molecular methods having good specificity are more preferable for diagnosing extra pulmonary tuberculosis as they give results before conventional gold standard method-culture- that is within few hours only. The good sensitivity of body fluids, pus and tissue shows better future aspects because at these sites bacilli are less and they frequently get missed in microscopy and culture.

Molecular methods are revolution for diagnosis of tuberculosis. In present era prevalence and morbidity of extra pulmonary tuberculosis have increased than pulmonary tuberculosis. This enlightens the importance of rapid and reliable diagnosis of the disease by PCR. Once trained, it needs less man power and is comparatively less tedious job in comparison to culture with differentiation between dead and alive bacilli.

\section{Conclusion and limitations}

PCR is still a good for extra pulmonary tuberculosis even if CBNAAT is available. Advantage of PCR over CBNAAT is that in PCR one can use unprocessed sample for other bacterial or viral panel diagnosis if PCR shows negative results as sometime cause may be other than tuberculosis when clinical picture shows so. But in CBNAAT it is not possible as whole sample is to be used. More such studies should be done to assess effectiveness of PCR in comparison to conventional methods. Even more comparative studies should be done between PCR, CBNAAT, LAMP and other molecular methods, so that in future we will have the best option for diagnosis of extra pulmonary tuberculosis without much more false negative results. This will again increase the possibility of microbiological diagnosis of tuberculosis than clinical suspicion.

Apart from body fluids, rest other sample's size was too small to comment well. Clinical correlation could have been done if it was a prospective study.

\section{References}

1. Arora VK, Chopra VK. Extrapulmonary tuberculosis. Indian JTuberc. 2007;54:165-7.

2. Delhi N. Indian Journal of Tuberculosis. Tuberculosis [Internet]. 2010;57(2):7-9.

3. Hillemann D, Rüsch-Gerdes S, Boehme C, Richter E. Rapid molecular detection of extrapulmonary tuberculosis by the automated genexpert MTB/RIF system. J Clin Microbiol. 2011;49(4):1202-5.

4. Honoré-Bouakline S, Vincensini JP, Giacuzzo V, Lagrange PH, Herrmann JL. Rapid Diagnosis of Extrapulmonary Tuberculosis by PCR : Impact of Sample Preparation and DNA Extraction Rapid Diagnosis of Extrapulmonary Tuberculosis by PCR : Impact of Sample Preparation and DNA Extraction. J Clin Microniology. 2003;41(6):2323-9.

5. Makeshkumar V, Madhavan R, Narayanan S. Polymerase chain reaction targeting insertion sequence for the diagnosis of extrapulmonary tuberculosis. 2014;(January):161-6.

6. Mehta CPK. Diagnosis of extrapulmonary tuberculosis by PCR IMMUNOLOGY \& MEDICAL MICROBIOLOGY. 2012;66:20-36.

7. Chakravorty S, Sen MK, Tyagi JS. Diagnosis of extrapulmonarytuberculosis by smear, culture, and PCR using universalsample processing technology. J Clin Microbiol.2005;43:4357-62.

8. Maurya AK, Kant S, Nag VL, Kushwaha RAS, Dhole TN.Detection of $123 \mathrm{bp}$ fragment of insertion element IS6110Mycobacterium tuberculosis for diagnosis of extrapulmonarytuberculosis. Indian J Med Microbiol. 2012;30:182-6.

9. Ganavalli SA, Shetty PC, Kulkarni RD, Biradar U. Pcr as a diagnostic tool for extra-pulmonary tuberculosis. J Clin Diagnostic Res. 2013;7(6):1012-5.

10. Amin I, Idrees M, Awan Z, Shahid M, Afzal S, Hussain A. PCR could be a method of choice for identification of both pulmonary and extra- pulmonary tuberculosis. 2011;0-4.

11. Bhanu, N. V., Singh, U. B., Chakraborty, M., Suresh, N., Arora, J., Rana, T., Takkar, D. \& Seth, P. (2005). Improved diagnostic value of PCR in the diagnosis of female genital tuberculosis leading to infertility. J Med Microbiol 54, 927-31.

12. Gupta, N., Sharma, J. B., Mittal, S., Singh, N., Misra, R. $\&$ Kukreja, M. (2007). Genital tuberculosis in Indian infertility patients. Int J Gynaecol Obstet 97,135-8.

13. Sharma, J. B., Roy, K. K., Pushparaj, M., Kumar, S., Malhotra, N. \& Mittal, S. (2008). Laparoscopic findings in female genital tuberculosis. Arch Gynecol Obstet 278,359-64.

14. Abebe, M., Lakew, M., Kidane, D., Lakew, Z., Kiros, K. $\&$ Harboe, M. (2004). Female genital tuberculosis in Ethiopia. Int J Gynaecol Obstet 84,241-6.

15. Abdul M, Siddiqui M, Anuradha PR, Nagamani K, Vishnu PH. Original article Comparison of conventional diagnostic modalities, BACTEC culture with polymerase chain reaction for diagnosis of extra-pulmonary tuberculosis. 2013;3(2):53-8. 